Fanum

Sociológico

\section{Forum Sociológico}

Série II

$24 \mid 2014$

Circulação de saberes e desafios em saúde

\title{
Círculos em Redes: da construção metodológica à investigação em saúde como pesquisa-formação
}

Circles in nets: From the methodological construction to the investigation in health as a formation-research

Ricardo Burg Ceccim, Guilherme Souza Müller, Laura Pereira da Maia and Ricardo Verza Cataluña

\section{CpenEdition}

\section{Journals}

Electronic version

URL: https://journals.openedition.org/sociologico/1111

DOI: 10.4000/sociologico. 1111

ISSN: 2182-7427

Publisher

CICS.NOVA - Centro Interdisciplinar de Ciências Sociais da Universidade Nova de Lisboa

Electronic reference

Ricardo Burg Ceccim, Guilherme Souza Müller, Laura Pereira da Maia and Ricardo Verza Cataluña,

"Círculos em Redes: da construção metodológica à investigação em saúde como pesquisa-

formação", Forum Sociológico [Online], 24 | 2014, Online since 16 November 2014, connection on 29

March 2022. URL: http://journals.openedition.org/sociologico/1111 ; DOI: https://doi.org/10.4000/

sociologico. 1111

This text was automatically generated on 29 March 2022.

(c) CICS.NOVA 


\section{Círculos em Redes: da construção metodológica à investigação em saúde como pesquisa-formação ${ }^{1}$}

Circles in nets: From the methodological construction to the investigation in health as a formation-research

Ricardo Burg Ceccim, Guilherme Souza Müller, Laura Pereira da Maia and Ricardo Verza Cataluña

\section{Introdução: a pesquisa como dispositivo de aprendizagem}

O desenvolvimento científico e tecnológico na investigação em saúde se refere, em geral, às atividades de pesquisa clínica, biomédica e de saúde pública explicadas em uma razão médica, ou racionalidade científica moderna ${ }^{2}$, em que é vigente o ideal de uma história natural das doenças e da cura, e um arcabouço interpretativo referido às determinações do processo saúde-doença. Nesse sentido, a terminologia genérica Pesquisa em Saúde, seja sob os métodos qualitativos, quantitativos ou mistos, supõe riscos à integridade física ou moral dos participantes, e não a mais profunda interação com os usuários das ações e serviços de saúde ou população. Em geral, a Pesquisa em Saúde explora uma pergunta originada no pesquisador ou grupos de pesquisa e não em projetos de encontro extenso e intensivo com os trabalhadores/usuários das ações e/ou serviços de saúde. Em geral, as ditas necessidades sociais terminam em decisões de quem porta a pergunta científica e justifica seu percurso investigativo junto às agências de fomento, mesmo que em defasagem de inéditos e criativos encontros com usuários das ações e/ ou serviços de saúde e seus trabalhadores. Essas pesquisas aprofundam disciplinas do conhecimento nas quais os usuários das ações e/ou serviços de saúde podem ser participantes (pacientes e portadores de eventos sob monitoramento), mas não parceiros em propostas de produção do conhecimento (algo que, com qualidade, pertenceria ao 
saber do pesquisador). Os trabalhadores são, igualmente, participantes (informantes), não parceiros das propostas de produção do conhecimento.

Distanciando-nos desse em geral, ocorre-nos a discussão dos referenciais da investigação participativa e da pesquisa-intervenção que adotam perspectivas sociopolíticas e de transformação social na produção de conhecimento aprofundado ou inovador, tendo lugar na saúde predominantemente na educação popular e na saúde comunitária. Essas abordagens podem buscar a interferência coletiva na produção dos modos de saber e constroem processos de mudança como atos de conhecimento: efeitos de saber que se espera de um leitor ou estudioso de relatórios de pesquisa acontecem entre participantes e parceiros que, estudiosos ou não, apropriam-se do conhecimento de maneira construtiva.

Então, a distância de certo em geral exige-nos uma problematização permanente ou in $a c t u^{3}$, posto que o saber ou conhecimento só existem em reverberação para todos os atores em cena, atores em implicação, atores em disputa nos planos de saber-poder e subjetivação, todos passíveis de entrada em devir, desestabilização ou agenciamento coletivo de enunciação.

4 Assim, o pesquisar poderia instaurar um exercício de acoplamento das teorias (saberes formais) e memórias (saberes da experiência) locais e, ainda, um exercício de acoplamento das perguntas de pesquisa e questões de si, dos encontros e de mundo (um processo de formação: educativo, de subjetivação e de composição de saberes). É necessário inserir na razão científica em saúde uma visão ampliada dos campos de saber científico e tecnológico aplicados e o respeito à pluralidade metodológica, possibilitando a utilização de diferentes abordagens de pesquisa, incluindo as de natureza qualitativa e de ciências humanas, além de componentes participativos nos quais pesquisador(es) e pesquisado(s) compõem estratégias formativas individuais, coletivas e institucionais. Pela Educação, e na saúde, introduzimos um critério ético: que mundo criamos com a pesquisa que fazemos?

5 Em nossa trajetória, e ao longo deste texto, trabalhamos na construção educossanitária do problema de pesquisa em saúde, produzindo-o em conversas colaborativas, na ativação de processos de pensamento e mediante conexões de saberes. Assumimos que o problema educossanitário não é biológico, psicológico, sociológico ou antropológico; é de pensamento, de construção cognitiva e afetiva, intelectual e sensível, processual, de aprendizagem e desenvolvimento, de interrogação de saberes, fazeres e perspectivas. Tal problema não antecede o percurso; ele emerge junto do percurso, do estranhamento de uma realidade e da urgência em perscrutar análises, experiências e correlações intelectuais. Como emergência, o problema é do âmbito da aprendizagem e estranhamento do mundo. A elevação do conhecimento não se refere a uma superior informação que se devolve à realidade, mas a um saber impregnado de realidade, sensível aos seus operadores sociais em redes de cotidianos.

6 Nesse sentido, no âmbito do Grupo de Pesquisa Educação e Ensino da Saúde ${ }^{4}$, temos proposto que a educação e ensino da saúde se integram ao trabalho em saúde em um ciclo formação-trabalho-formação, no qual se colocam a formação profissional básica, o exercício profissional do trabalho e a educação continuada para o aperfeiçoamento do trabalho e da profissão. Esse ciclo tem operado como um círculo vicioso, devido às características clínica, biomédica ou higienista - centradas, desencadeadas na formação, afirmadas no trabalho e retomadas nas estratégias de educação continuada. Tais características informam a atualização da formação básica, que incide sobre o 
trabalho, no qual emergem necessidades de educação contínua. A reduzida capacidade da pesquisa de inserir estranhamentos nesse ciclo está no fato de que a pesquisa em saúde, clássica ou crítica, contribui para sua manutenção, não para sua problematização. Trabalhamos, então, por outro ciclo, esse como círculos em redes, acoplando pesquisa e formação, designando-o por mandala educossanitária ao longo da nossa experiência no EducaSaúde. Associadas, a imagem da forma da mandala (círculo mágico, em sânscrito) e a imagem da quadratura do círculo (imaginário matemático de acoplamento do volume de um círculo no volume de um quadrado) permitem reconhecer a produção do saber como resultante de dados complexos que se enunciam como conhecimento (enquadrável em alguma forma do saber), mas também como aprendizado (imensurável e imaterial) e permeabilização ao estranhamento. É a pesquisa da realidade em saúde como investigação-ação e como aprendizagem em ato de pensamento provocado pela participação; por isso, essa pesquisa da realidade em saúde como pesquisa-formação.

7 A proposta da construção educossanitária do problema de pesquisa, por meio da produção científica, tecnológica ou artística, acentuou nosso debate acadêmico na perspectiva de um nosso conceito de base, o de Quadrilátero da Formação em Saúde (Ceccim e Feuerwerker, 2004). Aí propomos que a formação afeta, em intercessão, os âmbitos da atenção, da participação e da gestão em saúde ao interrogar as ações e os saberes atuados pelos diversos atores sociais das práticas. Todas as ações e saberes, todos os atores sociais das práticas e todos os parceiros em atividades de pesquisa estão em constante produção e em múltiplos movimentos quando integrados em círculos de pensamento e redes de conversação nos quais podem iniciar conexões ativas de tensão sobre as formas dadas e as invenções em emergência. Assim, a participação em conversas investigativas dispara atividades de trabalho, desenvolve estratégias de comunicação em rede e contribui à difusão de saberes disruptores nos e para os círculos de pensamento, funcionando como temas de dobradiça que reensejam a necessidade de redes de conversação.

Os círculos em redes surgem como metodologia capaz de provocar o diálogo entre pares, em rede, além de dobrar e desafiar saberes instituídos. A produção científica fica representada pela atividade de investigação-ação em círculos de pensamento e dos círculos de pensamento em redes científicas. Como parte do rigor metodológico e científico, do ponto de vista da construção educossanitária do problema, esse método caracteriza-se por uma abordagem qualitativa, como em estudos transversais, de tipo descritivo e de modelo exploratório. Exploram-se circunstâncias cujos limites não estavam dados, exceto na medida em que os encontros forem ocorrendo pelos caminhos emergentes em situação. Não se supõem limites claramente definidos, nem traçado já planejado, nem roteiro estruturado; trabalha-se com um organizando, algo distinto de um plano organizado. Portanto, o processo envolve a produção do conhecimento científico em associação livre, negociações entre atores, avizinhamentos entre pesquisadores, estratégias de interligação do maior número de elementos que deem viabilidade à construção do conhecimento e, simultaneamente, educação permanente em saúde: pesquisa-formação e pensamento-ação. 


\section{Círculos, redes e dobradiças na pesquisa-formação em saúde}

9 A noção de círculos e redes na pesquisa científica está presente nas formulações em ensino/aprendizagem, especialmente na Educação como Prática da Liberdade, tal como em Freire (2008), com os círculos de cultura, ou em Rocha (2000), com a pedagogia da roda, e na Ecologia Cognitiva de Lévy (1998) sobre a inteligência coletiva. Afirma-se que ninguém pensa sozinho, que todo pensamento é nó e circuito de redes de conhecimento. o conhecimento se produz coletivamente e mediante o contato com a diversidade.

o contato com a diversidade pode resultar de intervenções dobradiça, conceito que transformamos de Freire (temas de dobradiça), tanto quanto o conceito de círculos de pensamento (círculos de cultura na obra do educador). Os círculos de cultura são reuniões de grupos de interesse com o objetivo de discutir assuntos que tratem da temática trazida pelo grupo, tendo a presença do mediador (mediador que busca os dilemas de pensamento, não para a tomada de consciência, mas para a desacomodação intelectual). Os temas de dobradiça são como polemizações, conversas acrescentadas pelos agentes de problematização, funcionando como desconforto intelectual, que têm fundamento em Schwartz (2000), embora a nomenclatura de Freire (2008; FreireDowbor, 2000). A dobradiça busca o lugar da imagem de Lygia Clark (1960) com a introdução de dobradiças na escultura, de modo a derrubar a permanência da forma e introduzir um problema ao observador da obra de arte. Que forma quer ou considera o observador? Se a artista (o pesquisador) tem uma pergunta problemática que a faz criar uma obra de arte, esta mesma artista (este mesmo pesquisador) desafia o observador com seu problema de pesquisa e só manipula a obra com sua pergunta (quantas e quais formas pode a obra, por exemplo). 0 observador não pode responder sua pergunta, nem compreender a pergunta e resposta da artista, sem experimentar: seu pensamento precisa ser também ação de interação ${ }^{5}$. Os temas de dobradiça, de Freire, constituem a contribuição do educador, que introduz outros temas para auxiliar e enriquecer a compreensão do grupo. Um efeito de dobradiça em círculos de pensamento seria o momento do abalo na cultura, a quebra na cultura prévia ou o colapso no regime discursivo que dava forma ao vazio-pleno (uma forma só tem sentido por sua estreita ligação com seu espaço interior, o vazio-pleno). Esse colapso aparece na obra de Varela (1990) como perturbação, rachadura na continuidade cognitiva, que é da ordem do imprevisível e é potência para o nascimento do novo, para o reencontro como o préverbal, pré-pessoal, abertura e luta pela sobrevivência diante de um problema recémdescoberto/vivido.

11 Portanto, novos agregados conceituais no debate de dados ou de interpretações arrematam algumas posições já organizadas, polemizam eticamente dados e interpretações, introduzem problemas inéditos e configuram o que designamos por situação-dobradiça (construção da problematização de fatos, utopias, nós críticos e potências) - conceito que inventamos pelo experimentar da pesquisa por círculos em redes. Passamos a falar em situação-figura (círculo de pensamento inicial ou círculo de cultura) e situação-dobradiça (círculo de pensamento retomado em rede ou entre locais: círculos em rede). Depraz, Varela e Vermersch (2003) denominaram essa experiência cognitiva como ciclo básico do descondicionamento, ocorrendo a suspensão do julgamento habitual, o redirecionamento da atenção e o deixar-vir. 
12 Sobre as redes, Latour (2000) diz que essas viabilizam interações que formariam uma teia de aliados para saber mais, saber o não sabido, proporcionar a possibilidade de acesso aos insumos requeridos, ajudar nos processos de aperfeiçoamento necessários, ensejar disposições psíquicas para saber o que não tinha existência em nosso plano prévio de saberes. Latour fala de redes de translação porque a ação que se dá em ou através das redes não supõe homogeneidade: a ação coletiva e fruto da cooperação renovam as diferenças, singularizando-as. Ainda que atuem em coprodução, todas as instâncias participantes diferem entre si e diferenciam-se como resposta à coprodução.

13 Por sua vez, Lévy (1994: 163-175) coloca que o conhecimento se realiza pelo encaixamento fractal das aprendizagens: aí não há um encadeamento sequencial (complexidade crescente ou importância ascendente) e todos os tipos de produção coletiva devem ser utilizados e incentivados. Não é uma metáfora ou figura de retórica, menos ainda uma contradição, dizer que um dado coletivo ou grupo, em conjunto, pensa ou conhece. Lévy atesta: o pensamento já é sempre a realização de um coletivo (1994: 169).

14 Para Maturana (2001), o domínio cognitivo é conhecimento e paixão, o conhecimento feito em linguagem é resultado de emoção e, como tal, é uma rede de conversações. $\mathrm{O}$ autor reúne como conhecimento afirmações e explicações validadas pela paixão de aprender. A emoção fundamental - que especifica o domínio de ações no qual a ciência acontece como uma atividade humana - é a curiosidade. Varela, Thompson e Rosch (1992) colocam o domínio cognitivo na atuação do conhecimento, que se constitui como um operar de si e das realidades. Aí aprende-se com o corpo, a razão não se desenvolve fora da experimentação dos modos de saber. Varela (1990) lançou mão do conceito de enação (um neologismo em inglês: enaction ${ }^{6}$ ) para esclarecer as novas compreensões acerca da cognição. 0 sistema cognitivo enfrenta sua tarefa não pela incorporação de representações, mas pela atuação do conhecimento.

15 A aprendizagem pela resolução de problemas, que implica um mundo bem definido, abandona a cena contemporânea porque as questões que surgem a cada momento da vida não são prédefinidas, mas enatuadas (postas em ato). A noção tradicional de aprendizagem se assenta sobre a noção da falta, na lógica pedagógica do aprender resolvendo problemas, isto é, entrar em contato com a falta, a ausência, e investir o desejo na solução do problema, suprir a falta. No enfoque enativo, não há separação entre atuação de si e atuação do mundo. Fazer emergir a si mesmo é fazer emergir o mundo. Assim, o que faz agir não é a carência, mas a plenitude, o campo de possíveis, o ilimitado.

\section{Pesquisa-formação: um dispositivo de investigação vinculado à formação e às práticas por novas análises e ações}

Sachs (2003), discutindo o trabalho docente, sugeriu a pesquisa-ação como profissional ativista, sustentação à militância pelo ensino, escolas e educação de melhor qualidade. A pesquisa-ação como profissional ativista seria uma forma responsável de articular vários grupos interessados em trabalhar coletivamente e de forma colaborativa. Por intermédio das estruturas, processos e relações em uma profissão ativista, os ativistas de mudança social poderiam mover sentimentos públicos em uma direção progressista, 
envolvendo meios de comunicação e grupos comunitários diversos, no interesse político de uma prática inteligente e socialmente responsável.

A pesquisa voltada para a ação ou participação, inaugurada na América Latina por FalsBorda (1980), postulava o estudo-ação, uma postura de devolução do conhecimento aos grupos que deram origem a esse conhecimento e que dele foram expropriados pelas relações sociais de exclusão. Segundo o autor, o pesquisador aprende não apenas por meio daquilo que observa, mas pelo próprio trabalho com as pessoas com quem se identifica. A designação Pesquisa-Ação Participante afirma uma metodologia investigativa onde ocorre um processo vivencial junto aos grupos de base aos quais se destina e que inclui simultaneamente educação de adultos, pesquisa científica e ação política.

18 A proposição de Oddone (1986) sobre as Comunidades Ampliadas de Pesquisa veio de sua experiência junto ao movimento operário italiano, onde o saber deveria se consolidar pelas alternâncias entre o saber dos trabalhadores e o saber dos pesquisadores. Os encontros ampliados de pesquisa serviriam à discussão/compreensão acentuada dos estudos da realidade, funcionando como uma pedagogia da alternância, diálogo e confronto entre atores de polos diversos de formulação, implicação e agenda pública, consolidando uma experiência de formação em pesquisa e a construção de uma comunidade científica ampliada. Schwartz (2000) situa precisamente este conceito, o de Comunidade Científica Ampliada, referindo que construção de conhecimento e produção de saberes tem como pano de fundo a localização de um desconforto intelectual. Então, aprende-se na formação, na pesquisa e na intervenção.

Pimenta (2005: 529) denomina Pesquisa-Ação Crítico-Colaborativa uma forma de pesquisa qualitativa interventiva, associada à formação dos atores sociais que participam das observações do pesquisador e que contribuem na formulação das conclusões, partilhando e contribuindo do conhecimento produzido, constituindo-se em pesquisadores e autores das mudanças resultantes do conhecimento. Ação e investigação são concebidas e desenvolvidas ao longo de um processo que se constrói em círculos de reflexão e espirais de ação, conformando a produção do conhecimento em estratégias de pensamento e de prática social. A proposta metodológica que aprendemos da autora é a da formação no constructo da educação permanente, da produção do conhecimento crítico-colaborativo na qual, ao final da pesquisa, os atores sociais da implicação aprendem a pesquisar sua realidade e a construir conhecimento atual a partir de suas próprias vivências. A educação permanente é o mote de acesso ao grupo social, uma forma de colaborar e não apenas extrair informação, servindo à devolução social dos dados da pesquisa simultânea à obtenção desses dados, ao mesmo tempo colocando os mesmos ou sua interpretação em análise. A pesquisa alcançaria o estatuto de rede de redes, armando sistemas de informação e comunicação entre núcleos de estudo-ação. Considerando a peculiaridade da proposta pedagógica da pesquisa envolvendo formação e produção de conhecimento por meio da problematização de práticas, saberes, experiências e vivências, o estudo deixa, no ato da pesquisa, atores preparados para o ensino e a investigação científica.

Warschauer (2001), ao perguntar quem educa o educador, propôs a imagem das Rodas em Rede, um modo de pesquisar para que possamos nos repensar. A roda é utilizada como o lugar do descobrimento de dados. A autora entende essa concepção como partilha, trazendo a ideia de retorno à pessoa, na qual o que importa são os significados e os aprendizados que elas fazem, uma partilha onde despontam trocas por reciprocidade ética 
não mercantil. Do saber por rodas em rede surgiria a pauta de temas à formação em serviço ou à formação implicada com uma realidade. Uma estratégia pedagógica que permitiria dar escuta àqueles que compõem efetivamente o cenário do trabalho na saúde, do mesmo modo que na educação.

Rocha e Aguiar (2003: p. 65) colocam que a pesquisa-ação crítica está centrada no agir, por meio de uma metodologia exploratória, tendo seus objetivos definidos no campo de atuação pelo pesquisador e pelos participantes, se justificando na tomada de consciência dos fatores envolvidos nas situações de vida imediata, cujos resultados estariam na participação coletiva para a mudança da ordem social. Para as autoras, entretanto, as múltiplas determinações das posições de sujeito descaracteriza(ra)m um estado privilegiado de consciência para o qual se pudesse levar o outro a ser conscientizado. Se o poder passa a ser pensado como produção de subjetividade, é nas condições políticas que se produzem sujeitos, domínios de saber e relações com a verdade; portanto, não se tratará mais de conscientizar, mas de descentrar o poder de um sujeito verdadeiro para colocar em análise os processos de sua constituição como tal.

Um aprofundamento importante dos componentes ação, participação e produção ativa de conhecimento está na denominada Pesquisa-Intervenção, marcadamente representada pelos autores do campo da Análise Institucional. Um descritor relevante da PesquisaIntervenção é seu caráter desarticulador das práticas e dos discursos instituídos, invertendo-se a máxima conhecer para transformar em transformar para conhecer (Coimbra, 1995). Para a formulação da Pesquisa-Intervenção, são conceitos estratégicos o de analisador e o de implicação. A realidade não é estática e nem deve ser reapresentada como se interessasse encontrar seus fixos; tampouco o pesquisador é neutro e sua implicação compõe os passos da pesquisa, sua revisão e dimensões, ampliando as bases teórico-metodológicas de pesquisas com proposta de atuação transformadora da realidade sociopolítica. O que se coloca em questão é a construção de uma atitude de pesquisa que irá radicalizar a ideia de interferência entre sujeitos e sobre objetos, condição ao próprio conhecimento. Rodrigues e Souza (1987) reivindicam que a Pesquisa-Intervenção se constitui com uma importante diferenciação das bases primeiras da pesquisa-ação, portando-se como pesquisa-ação crítica e, além disso, necessariamente participativa e comprometida com a educação de seus atores sociais. $\mathrm{Na}$ pesquisa-intervenção, segundo as pesquisadoras, acentua-se todo o tempo o vínculo entre a gênese teórica e a gênese social dos conceitos, que é negado implícita ou explicitamente nas versões positivistas "tecnológicas" de pesquisa (Rodrigues e Souza, 1987: 31).

Esse conjunto de sentidos e desafios à pesquisa, e a rede de interlocuções demoradamente armada, nos levou a denominar uma construção singular de método científico à pesquisa: Círculos em Redes. Círculos de pensamento e intervenções dobradiça para emergir enunciados e visibilidades, postos em Redes de conversação e inteligência cooperativa. Círculos em redes como rodas de conversação e redes colaborativas transversais, que não levam a uma tomada de consciência, mas a dilemas em reverberação. $O$ método pressupõe a coordenação de atividades de conhecimento e a compreensão da necessidade do desenvolvimento e implantação de recursos interativos que propiciem uma inteligência cooperativa entre atores, além da utilização de mecanismos que subsidiem a troca de experiências e o desenvolvimento de tecnologias colaborativas. Por isso, mandalas educossanitárias (atores da implicação científica, trama de teias de 
inserção de cada ator, produção de sentidos coletivos, conhecimentos heterogêneos e práticas singulares), educação e saúde em intercessão.

Com círculos e redes e com redes de círculos estabeleceu-se a noção de círculos em redes. Não apenas discursos se formam, mas atores emergem. Assim, enunciados não são discursos, mas práticas éticas; visibilidades não são imagens, mas práticas estéticas. Uma vez coletivas, práticas ético-estéticas permitem a emergência de uma política do conhecimento, não o conhecimento puro e simples, desencarnado da ação. 0 conhecimento se dissemina por teias, também em um movimento por círculos de pensamento ou por círculos sociais de cultura, espontâneos ou não. A investigaçãointervenção ou a produção de conhecimento científico estará na capacidade da pesquisa de agenciar heterogeneticamente saberes e aprendizagens, ocupando-se das dimensões coletivas do pensamento e da cognição, valorizando as inteligências distribuídas por todos os atos e instâncias interativas.

Com os círculos em redes admite-se uma postura científica de provocar a conversação; criar um meio de cultura para a atividade de pensamento; um processo educacional e uma trama em tecedura de saberes. A assunção crítica da condição de círculos de pensamento em redes de conversação para a ação de produção de conhecimento, especialmente o conhecimento implicado, isto é, aquele conhecimento que deseja operar práticas sociais - cuja função social é a produção de redes de conectividade -, permite-nos pensar a pesquisa-formação.

o desafio do conhecimento, ao contrário de buscar a revelação das verdades e a transformação pelo esclarecimento, aproxima-nos dos defasamentos de si, problematização das verdades e desnaturalização das explicações. Aguiar e Rocha (2007: 653) resumem que pensar não é uma questão de vontade, é um exercício que se dá por provocação. As autoras, junto com Cláudio Ulpiano, dizem que o pensar ocorre nos encontros com o inusitado, nos afetos deslocados, na tensão entre o que já ganhou forma como homem e mundo, sujeito e objeto e o que vai se produzindo, evocando novas formas. As análises de pensamento são vetores que evidenciam forças em luta, não apenas a nãoconformidade com os instituídos, mas a constituição dos instituídos, a desnaturalização das formas e a desestabilização dos ordenamentos que as justificavam.

No desafio do conhecimento, a não isenção ou não neutralidade do pesquisador/pensador não se refere à não politização de suas implicações; ao contrário, permitem a problematização em rede de conversação de sua pesquisa-intervenção, tornando-a pesquisa-formação porque aberta às interações por ressingularização. Saindo de um eixo da pesquisa-intervenção, que atua na realidade para transformá-la mediante suas restituições contributivas para a tomada de consciência, podemos construir o desenvolvimento intelectual pela atuação do pensamento. Um pensamento vivo ou em ato experimenta (não observa) a realidade. Quando a realidade se torna campo de problematização, o campo se torna experimentação do pensamento, facultando novos modos de apreensão-produção do real (Aguiar e Rocha, 2007: 653). Sem inscrever (dar forma) enquanto intervém, mas acentuando casos de pensamento, o pesquisador apreende, aprende e ensina sobre vazamentos e produção de contornos. 


\section{Inteligência como as diagramações da mandala educossanitária}

Uma metodologia de círculos em redes contempla segmentos (guarda semelhança com a noção de etapas, exceto pelo fato de que não são invariantes e sequenciais; aqui, etapas deslizam, se insurgem, se perseguem) absorve um movimento cognitivo construtivista e uma estética da mandala. No ciclo da pesquisa correm dados, informação, problematização e conhecimento, mas na condição de fluxos, não de fixos. Ao longo do processo de pesquisa, configura-se um ciclo da inteligência, deixando de ser um processo coletivo de transformação participativa; torna-se uma análise das figuras de realidade (reconhecimento das configurações em ato de uma realidade) e engendramento de linhas de reconfiguração dessa mesma realidade em direções produtoras de sentido (um para onde, não um para o quê). No ciclo da inteligência da pesquisa-formação, temos um momento basal na atenção e um momento operativo na construção de conhecimento, passando pela coleta/produção de dados, seleção/ expressão de informações, descoberta/construção de conhecimento e emergência/ produção de inteligência, desenvolvendo capacidade de pensar, não apenas de raciocinar (reordenar, rearranjar), assim operando realidades por atualidade, sempre em recomposição/reconfiguração.

29 A pesquisa é assumida em seu componente laborioso: olhar para realidades, destacar (produzir) informações a respeito delas, gerar estratégias para captar as virtualidades (os devires), estabelecer circuitos (redes explicativas e redes de intervenção) e, assim, assistir ao desdobramento de figurações: a tomada de cena, os pontos em que se entrou em produção, os pontos em que se entrou em processo (crises) e os pontos em se entrou em recomposição (criação).

30 Estão na rede de explicações e de intervenções os diferentes atores sociais (formuladores, gestores, trabalhadores, usuários, docentes, estudantes, movimentos sociais, financiadores, fóruns, comissões); documentos institucionais e históricos; material instrucional; relatórios; documentos de prestação de contas; comunicações e conversações colaborativas; leitura e revisão bibliográfica sobre o campo semântico implicado e intercâmbio de teorias; discussão coletiva dos instrumentos e elaboração de instrumentos qualitativos diferentes para a diversidade de atores; muitas reuniões para compatibilização das informações quantitativas e qualitativas; valorização e relativização dos achados por olhares terceiros (consultorias, debates externos) etc. Lembramos da imagem da mandala na educação dos profissionais de saúde: um quadrilátero onde colocamos Gestão - Atenção - Participação - Formação, um círculo que abrange, por implicação, o quadrilátero, mas o excede por todos os lados, caracterizando o seu fora, forçando, contra a vontade ou em corpo-a-corpo, o pensamento (Ceccim e Feuerwerker, 2004).

31 A sistemática que foi descrita como círculos em redes passa a corresponder a uma ativação da inteligência coletiva (a inteligência como competência, não o conhecimento como uma acumulação):

32 - Análise de Situação: anotação do contexto, identificação da estrutura e cultura local. Conceitos como pertencimento, pertinência, responsabilidade, vínculo e objetivos podem servir para orientar os instrumentos de coleta de dados. 

dados em informação pelo confronto com os objetivos, conceitos, arranjos de gestão e composição de coletivos. A figura ultrapassa a representação (as formas) expressando as forças que emergem de uma figura quando essa se desfigura (toda forma da realidade é uma configuração da realidade, não "a" realidade) ${ }^{7}$.

34 implicação no quadrilátero (pessoas, instituições e coletivos envolvidos com a situaçãofigura).

35 - Questões-problema: qual o levantamento das redes explicativas do problema (o que lhe dá a configuração atual?).

36 - Análise dos movimentos postos em rede: qual o levantamento e utilização das redes de intervenção (o que pode mudar uma configuração?).

37 - Situação-dobradiça: transformação das informações em conhecimento, mediante discussão ou debate (problematização da informação); formação de atores.

- Prospecção de situação: análise do que deve se tornar intervenção-ação (figuraçãoreconfiguração); pesquisa-intervenção em situação de formação.

- Situação-reconfiguração: redes de comunicação colaborativa para adensamento de interpretações, confronto de saberes preexistentes com a realidade analisada, análise de registros e construção de conhecimento, compreensão do contexto e produção de textos para o contexto. Localização de movimentos do quadrilátero no círculo mágico (dobras e desdobras da mandala); inteligência coletiva.

Desse modo, a pesquisa vai registrando a paisagem e a formação transformando essa paisagem; o pesquisador faz parte da transformação da paisagem; terá de registar os contornos e sua transformação. No percurso, será utilizada uma diversidade de recursos e técnicas mais amplas do que na investigação tradicional, bem como abordagens que podem gerar estranhamento à pesquisa tal qual se vem apresentando desde a modernidade (Ceccim e Ferla, 2005). É a busca de conhecimento na exterioridade da razão e da consciência, no compromisso ético e político com a vida e com a produção de mundo, que sugere a busca de conhecimento nos desafios do pensamento. Conseguimos ser dobradiça? Escutamos os cochichos disruptores (os mundos minoritários)? Conseguimos ser educadores em situação de pesquisa? Fica aí uma síntese de nossa acumulação na construção metodológica da investigação em saúde como pesquisa-formação. Reunindo pesquisa e formação, em círculos e redes, colocamos em cena o substrato cognitivo e afetivo do trabalho e do trabalhar em saúde, sua processualidade propriamente coletiva, suas operações de encontro. 0 dispositivo da inteligência, com as diagramações dos círculos em redes (ou da mandala educossanitária), se constitui num processo de conhecimento para pesquisadores, pesquisados e se introduz em suas redes de conversações. Por isso, esse é um modo de pesquisar que não busca a produção de conhecimento, simplesmente, mas a produção de inteligência. No mínimo, em tese, o que se deveria esperar da educação - nesse caso, aquela dirigida à saúde. 


\section{BIBLIOGRAPHY}

AGUIAR, K. e M. Rocha (2007), "Micropolítica e o exercício da pesquisa-intervenção: referenciais e dispositivos em análise", Psicologia, ciência e profissão, 27 (4), p. 648-663.

BERGSON, H. (1999), Matéria e memória: ensaio sobre a relação do corpo com o espírito, São Paulo: Martins Fontes.

CECCIM, R. e L. Feuerwerker (2004), “O quadrilátero da formação para a área da saúde: ensino, gestão, atenção e controle social”, Physis, 14 (1), pp. 41-65.

CECCIM, R. e A. Ferla (2005), "Notas cartográficas sobre a escuta e a escrita: contribuição à educação das práticas de saúde", in R. Pinheiro e R. Mattos (orgs.), Construção social da demanda: direito à saúde, trabalho em equipe, participação e espaços públicos, Rio de Janeiro, Abrasco, pp. 253-267.

CLARK, L. (1960), "Bichos", in L. Clark, O mundo de Lygia Clark: em 1960, Lygia escreve o texto sobre a fase que está desenvolvendo - Bichos, Três Rios, RJ: Associação Cultural O Mundo de Lygia Clark, 3p.

COIMBRA, C. (1995), “Os caminhos de Lapassade e da análise institucional: uma empresa possível”, Revista do Departamento de Psicologia da UFF, 7 (1), pp. 52-80.

DELEUZE, G. (2007), A lógica da sensação, Rio de Janeiro, Jorge Zahar.

DEPRAZ, N. et al. (orgs.) (2003), On Becoming Aware: a pragmatics of experiencing - advances in consciousness research, Amsterdam, John Benjamins Publishing Company.

FALS-BORDA, O. (1980), La ciencia y el pueblo, Bogotá, Punta de Lanza.

FREIRE, P. (2008), Pedagogia da esperança: um reencontro com a pedagogia do oprimido, São Paulo, Paz e Terra.

FREIRE-DOWBOR, F. (2000), "Paulo Freire, um precursor”, in BRASIL, Ministério das Relações Exteriores. Textos do Brasil, n. 7, mat. 3. Brasília, Ministério das Relações Exteriores, pp. 16-17.

LATOUR, B. (2000), Ciência em ação: como seguir cientistas e engenheiros sociedade afora, São Paulo, Unesp.

LÉVY, P. (1994) As tecnologias da inteligência: o futuro do pensamento na era da informática, Rio de Janeiro, 34

LÉVY, P. (1998), A inteligência coletiva: por uma antropologia do ciberespaço, São Paulo, 34

LUZ, M. (2012), Natural, racional, social: razão médica e racionalidade científica moderna, São Paulo, Hucitec.

MATURANA, H. (2001), Cognição, ciência e vida cotidiana, Belo Horizonte, UFMG.

ODDONE, I. et al. (1986), Ambiente de trabalho: a luta dos trabalhadores pela saúde, São Paulo, Hucitec

PIMENTA, S. (2005), "Pesquisa-ação crítico-colaborativa: construindo seu significado a partir de experiências com a formação docente”, Educação e Pesquisa, 31 (3), pp. 521-539.

ROCHA, M. e K. Aguiar (2003), "Pesquisa-Intervenção e a produção de novas análises", in Psicologia: ciência e profissão, 23 (4) pp. 64-73.

ROCHA, S. (2000), “A pedagogia da roda”, in Boletim Espacio para la infancia, Haia, Bernard van Leer Foundation - BLF, 13, p. 24-29. 
RODRIGUES, H. e V. Souza (1987), “A análise institucional e a profissionalização do psicólogo”, in O. Saidon e V. Kamkhagi (orgs.), Análise Institucional no Brasil: favela, hospício, escola, Rio de Janeiro, Rosa dos Tempos, pp. 17-35.

SACHS, J. (2003), The activist teaching profession, Buckingham, Open University Press.

SCHWARTZ, Y. (2000), “A comunidade científica ampliada e o regime de produção de saberes: trabalho e educação”, in Trabalho \& Educação (Belo Horizonte), 7 (2), pp. 34-46.

VARELA, F. J. (1990), Conocer: las ciencias cognitivas, tendencias y perspectivas - cartografia de las ideas actuales, Barcelona, Gedisa.

VARELA, F. J. et al. (1992), De cuerpo presente: las ciencias cognitivas y la experiencia humana, Barcelona, Gedisa.

WARSCHAUER, C. (2001), Rodas em rede: oportunidades formativas na escola e fora dela, Rio de Janeiro, Paz e Terra.

\section{NOTES}

1. Comunicação apresentada no V Congresso Ibero-Americano de Pesquisa Qualitativa em Saúde - Circulação de Saberes e Desafios em Saúde, realizado em Lisboa entre 11 e 13 de outubro de 2012.

2. Sobre razão médica e racionalidade científica, ver Luz, 2012.

3. Para um conceito de problematização, ver Bergson, 1999.

4. Educação e Ensino da Saúde é um Grupo de Pesquisa, cadastrado entre os Grupos de Pesquisa no Brasil, junto ao Conselho Nacional de Desenvolvimento Científico e Tecnológico - CNPq, resumido pela denominação EducaSaúde, com registro de propriedade intelectual à Universidade Federal do Rio Grande do Sul, e logotipia em diagrama de mandala. Disponível em: http:// dgp.cnpq.br/buscaoperacional/detalhegrupo.jsp?grupo=0192708JQZU3BK, acessado em 06 de fevereiro de 2013.

5. Sobre a relação entre observador e obra de arte em Lygia Clark, acessar: http:// www.lygiaclark.org.br/arquivo_detPT.asp?idarquivo=15.

6. Sobre enação, ver Varela (1990: 87-110).

7. Sobre figura, ver Deleuze, 2007.

\section{ABSTRACTS}

The article introduces the notion of circles in nets to amplify the possibilities of investigation in the field of health research. It contrasts the modern scientific rationality along with the educational-sanitarian problem, indicating to the necessity of collective construction of strategies of analysis and intervention in a given reality. The notion of circles in nets allows to acknowledge that the production of knowledge is a result of complex, multiple, plural, collective and collaborative data, which appear as knowledge itself, as learning and willingness for doubting. As a final remark, it indicates that the circles in nets are constituted within a process to researchers 
and researched people, becoming a mode of researching that do not seek the mere production of knowledge, but the production of collective intelligence.

$\mathrm{O}$ artigo introduz a noção de círculos em redes para ampliar as possibilidades de investigação no campo da pesquisa em saúde. Contrapõe a racionalidade científica moderna através do problema educossanitário, aludindo à necessidade da construção coletiva de estratégias de análise e intervenção em uma realidade. A noção de círculos em redes permite reconhecer a produção do saber como resultante de dados complexos, múltiplos, plurais, coletivos e colaborativos, que se enunciam como conhecimento, como aprendizado e disposição ao estranhamento. Ao fim, indicase que os círculos em redes se constituem dentro de um processo para pesquisadores e pesquisados, sendo um modo de pesquisar que não busca a produção de conhecimento, simplesmente, mas a produção de inteligência coletiva.

\section{INDEX}

Keywords: qualitative health research, educational-sanitarian problem, circles in nets, education in health, formative research, collective health

Palavras-chave: pesquisa qualitativa em saúde, mandala educossanitária, círculos em redes, educação na saúde, pesquisa-formação, saúde coletiva

\section{AUTHORS}

\section{RICARDO BURG CECCIM}

Sanitarista, mestre em Educação em Saúde, doutor em Psicologia Clínica e pós-doutor em Antropologia Médica, professor da Universidade Federal do Rio Grande do Sul - UFRGS, pesquisador na área de Educação e Ensino da Saúde, junto ao Conselho Nacional de Desenvolvimento Científico e Tecnológico - CNPq, Brasil (ricardo@ceccim.com.br)

\section{GUILHERME SOUZA MÜLLER}

Estudantes de graduação em Saúde Coletiva - Bacharelado, Universidade Federal do Rio Grande do Sul - UFRGS, bolsistas de iniciação científica e popularização da ciência na área de Educação e Ensino da Saúde, junto à Universidade e ao CNPq, Brasil 